\title{
From learning portfolios to personal development plans
}

\section{T Gibbs MBChB (Liverpool), FRCGP, DA (Educational Leadership), MMedSci, ILTM, FFHom , D Brigden MEd, M I Biol, ILTM \& D Hellenberg MBChB (UCT), MFamMed, MFGP (SA)}

To cite this article: T Gibbs MBChB (Liverpool), FRCGP, DA (Educational Leadership), MMedSci, ILTM, FFHom , D Brigden MEd, M I Biol, ILTM \& D Hellenberg MBChB (UCT), MFamMed, MFGP (SA) (2005) From learning portfolios to personal development plans, South African Family Practice, 47:5, 6-8, DOI: 10.1080/20786204.2005.10873224

To link to this article: http://dx.doi.org/10.1080/20786204.2005.10873224

\section{(c) 2005 SAAFP. Published by Medpharm.}

\section{曲 Published online: 15 Aug 2014.}

Submit your article to this journal

山 Article views: 29

Q View related articles $\sqsubset$ 


\section{From learning portfolios to personal development plans}

Gibbs T, MBChB ( Liverpool), FRCGP, DA (Educational Leadership), MMedSci, ILTM, FFHom Professor of Medical Education and Family Medicine, College of Medicine and Medical Sciences, Arabian Gulf University, Kingdom of Bahrain Brigden D, MEd, M I Biol, ILTM Visiting Professor of Professional Development, Faculty of Health Sciences, University of Cape Town; Adviser for Postgraduate Medical and Dental Education, Mersey Deanery, University of Liverpool, Liverpool UK Hellenberg $D$, MBChB (UCT), MFamMed, MFGP (SA)

Correspondence: Professor Derek Hellenberg, Professor of Family Medicine, Faculty of Health Sciences, University of Cape Town, Anzio Road, Observatory 7925, tel: 021406 6712, fax: 021406 6244, e-mail: dhellenb@cormack.uct.ac.za

Keywords: Learning portfolios; $p$

\section{Introduction}

Previous articles have focused on the need to recognise and implement modern educational theory in practice, to make learning a continuous, lifelong activity, and to relate learning to outcome measures. For each of these, the medical practitioner has to develop the appropriate tools for these concepts to be implemented and to be successful. But how do practitioners appraise what they have been involved with or map what they intend to carry out in the future, or make themselves ready for a future when accreditation and re-accreditation are realistic outcome measures?

In this article we put forward, for discussion, the use of modified learning portfolios, which, when combined with a personal development plan, act as an educationally directed developmental tool to identify educational and training needs, as well as to record individual progress and success. We will draw a comparison between this type of portfolio and the standard curriculum vitae, whilst demonstrating the potential for a learning portfolio to be a useful adjunct to a curriculum vitae.

"I always say, keep a diary and some day it'll keep you"- Mae West ${ }^{1}$

(SA Fam Pract 2005;47(5): 6-8)

\section{Discussion}

For the undergraduate and postgraduate alike, a learning portfolio is a collection of material brought together for a specific purpose..$^{2,3}$ Putting one together enables medical practitioners to take responsibility for identifying important past activities and recognising a need for future learning; allows them to identify gaps in their knowledge, experience and skills; and supports decisions on when and where training is required. The need for accountability is clear whether learning portfolios are used at an undergraduate level, where they are often used as assessment tools, ${ }^{4,5}$ at a postgraduate level, where they are used for professional development, ${ }^{6}$ or whether the learning activity is part of continuing professional development. ${ }^{7}$. As well as a record of achievements, the portfolio can be a tool for reflection on past learning experiences and for self-directed learning.

A record of personal development is often quoted as an essential component of medical postgraduate training in all fields, ${ }^{8}$ and a standard format for appraisal and assessment, in the form of a structured portfolio, has been proposed. ${ }^{9}$

By critically reviewing, analysing and evaluating our decision-making processes and our interaction with patients and colleagues as we progress through various activities, it is possible to develop a firm basis for implementing identified learning needs, as well as for recognising areas of improvement and even successes.

If portfolios are combined with personal development plans, they can be used to highlight extracurricular commitment and achievement, both at an undergraduate and postgraduate level; these facets are often used to enhance a curriculum vitae.

\section{What goes into a portfolio?}

The portfolio should be regarded as an active document that stems from and develops via a reflective process.

The evidence it presents should demonstrate:

- Positive aspects of learning activities and how these have either helped or enhanced the individual and his or her responsibilities within his or her post or future career

- Negative aspects of such activities and how these have been overcome 
- Identification of development needs and educational objectives (upgrading and updating knowledge and skills) and eventual outcomes

- The learning strategies to be used to fulfil learning needs, together with an appropriate timetable for future achievement

- A summary of any future learning resources required

The identification of learning needs is further developed by the consideration of critical incidents, awkward moments, important events, external priorities and previously conducted educational/portfolio appraisals.

By providing this window into both undergraduate and postgraduate medical development, a balance is demonstrated between evidence and reflection (see Figure 1). The portfolio should demonstrate a process of 'active learning', rather than a 'passive' passage through the medical education system, in a reliable, valid and standardised manner.

Fig. 1: The combined personal portfolio

- Personal details

- Examination certificates

- Summary of rotations and specific placements

- Career intentions

- Courses attended

- Research experience and aspirations (including research and other projects)

- Identified learning needs

- Future objectives and eventual outcomes

- Publications

- Case presentations

- Specific cases

- Memorable patients and events

- Updated and serialised CV

- Other (anything else relevant)

\section{Construction portfolio}

The following questions may serve as a guide in the process of constructing a personal portfolio:

- What does your past experiences (evidence) show and how are they related to personal development?

- Is the evidence relevant to your present career and future outcomes? (This should be succinct and directed.)

- Are you demonstrating competence in your field, and through what method?

- What is missing? (Identify gaps of knowledge, and targets.)

- What is to come? (How and when will you fill gaps.)

\section{The reflective process}

Personal development planning is part of the reflective process that is often employed by the teaching and medical profession. ${ }^{10,11}$ Reflection is a critical component of the learning cycle, involving association of that which is new with past experience, and thereby putting the meaning of a given experience into context. This is clearly something that is also central to medicine, with its emphasis on evidence-based medicine. The reflective process will add to the knowledge and skills we expect to learn by providing a means with which to interpret them within a professional rationale. Ultimately, we should be able to mould and modify our

approach to learning and the knowledge we have gained through reflection to optimise our approach.

Experiential learning cycles, such as those described by Kolb (see Figure 2), turn a subjective experience into a learning process and are used, for example, to structure experiencebased educational programmes. ${ }^{12}$ The personal portfolio can be based upon this model, empowering both the student and the practising clinician alike to govern their own learning needs.

\section{So why a personal portfolio and not a curriculum vitae?}

Asking an individual to list what they have done, despite being an assessment of some level of activity and acquisition of skills, is not necessarily a valid assessment of either need or performance. Brigden and Lamont bring to our attention that only through observation of the individual in the clinical setting would we truly be able to make an objective assessment of his or her performance. ${ }^{13}$ However, by asking individuals to reflect upon their experiences and relate them to both personal and organisational

Fig. 2: The Kolb Cycle of Experiential Learning

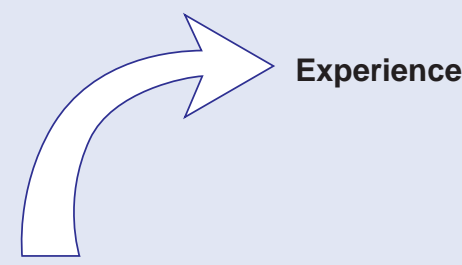

Planning

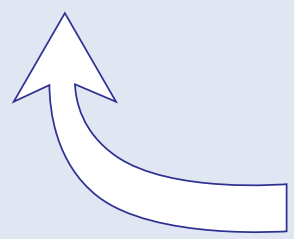

Conclusions

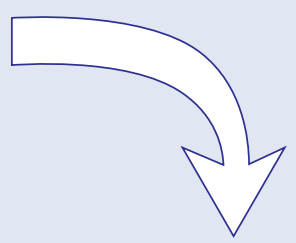

Reflection

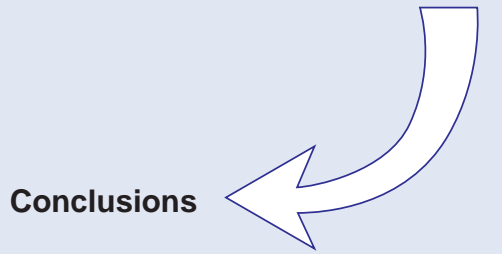

Experience: The experiences we gain during our development and/or part of everyday practice.

Reflection: Reflecting, looking over, what has been experiences or activities.

Concluding: Interpretation of events and relationships between them, applying concepts and placing them in context.

Planning: Predictions of what will happen next and direction. 
expectations and needs we begin to get a clearer picture of the individual; whilst the individual obtains a clearer picture of his or her educational needs.

We therefore suggest that the introduction of portfolios will serve as an adjunct to our current procedure of curriculum vitae construction, rather than to distance the individual from personal assessment, thereby aiding both the assessor and the assessed.

Senior medical students and practising clinicians in the United Kingdom are expected to adhere to and uphold the principles set down in the GMC document, Good Medical Practice, which is considered the basis of the standards required to be a good doctor. ${ }^{14}$

The South African Medical and Dental Professional Board has produced similar documentation, in which the principle areas for consideration are:

- Good clinical care

- Maintaining good medical practice

- Teaching and training

- Maintaining trust

- Working with colleagues

- Probity and honesty

- Health $^{15}$

The personal portfolio is an ideal instrument for recording such evidence, planning future needs and analysing in a quality assurance manner. Bringing together, within one folder, the documentary evidence of the range of experience, learning, education and training, as well as future needs and intentions, will be invaluable to personal development, as well as be a first step towards meeting the requirements for future interviews and appraisals, and easing the transition and conceptualisation from learning and training to the world of professional practice.

"The fault, dear Brutus, lies not within the stars, but within ourselves" Cassius $^{16}$

\section{Points to ponder}

- Personal, public and organisational accountability is now becoming standard practice

- Learning needs are based upon past experience and future expectations

- Reflection is an accepted prerequisite for accountability

- Standard CVs are a two-dimensional model of personal attributes; personal portfolios provide the third dimension of educational needs and future outcomes

- Compilation of personal portfolios should become standard practice for all medical practitioners

\section{References}

1. Mae West (1892-1980). From Every Day's a Holiday (movie released in 1937).

2. Challis M. AMEE Medical Education Guide No. 11 (revised): Portfolio-based learning and assessment in medical education. Med Teacher 1999;21:370-86.

3. Brigden DN. Constructing a learning portfolio. Career Focus, British Medical Journal 1999;7201:319.

4. Challis M. Portfolios and assessment: meeting the challenge. Med Teacher 2001;23(5):43740

5. Rees C, Sheard EC. The reliability of assessment criteria for undergraduate medical students' communication skills portfolio: the Nottingham experience. Medical Education 2004;38(2):138-44.

6. Melville C, Rees M, Brookfield D, Anderson J. Portfolios for assessment of paediatric specialist registrars. Medical Education 2004;38(10):1117-25.

7. Zeiger RF. Towards continuous medical education. Journal of General Internal Medicine 2005;20(1):91-4.

8. General Medical Council. The new doctor: recommendations on general clinical training January 2005: http://www.gmc-uk.org

9. University of Western Australia Medical School. The undergraduate medical curriculum: http://www.rcs.uwa.au

10. Jarzabkowski, P. Reflections on the role of reflecting: http://www.usyd.edu. au/su/ctl/Synergy/Synergy4/pjarzab.htm

11. Mathew-Maitch N, Brown B, Royle J. Becoming through reflection and personal portfolios: the voice of growth in nurses. Reflective Practice 2000:1(1):309-24.

12. Kolb DA, Rubin IM, Mclntyre JM Organisational psychology: an experiential approach to organisational behaviour. New Jersey: Prentice Hall; 1984.

13. Brigden DN, Lamont GL. Making assessment reliable and valid. Occasional Paper, Mersey Deanery Education Matters 16; 2003.

14. General Medical Council: Good medical practice. 3rd ed. May 2001. http://www.gmcuk.org

15. South African Mental and Dental Professional Board. Education and training of doctors in South Africa. Undergraduate medical education and training - Guidelines. September 1999.

16. Shakespeare W. (1564-1616) Julius Caesar Act 1 Sc 2 